\title{
Internal conflict, market uniformity, and transparency in price competition between teams $\star$
}

\author{
Michael Kurschilgen $\#, \S$, Alexander Morell§, and Ori Weisel ${ }^{+,}{ }^{*}$ \\ \#School of Management, Technical University of Munich \\ \$Max Planck Institute for Research on Collective Goods, Bonn \\ ${ }^{+}$Coller School of Management, Tel Aviv University
}

\begin{abstract}
The way profits are divided within successful teams imposes different degrees of internal conflict. We experimentally examine how the level of internal conflict, and whether such conflict is transparent to other teams, affects teams' ability to compete vis-à-vis each other, and, consequently, market outcomes. Participants took part in a repeated Bertrand duopoly game between three-player teams which had either the same or different level of internal conflict (uniform vs. mixed). Profit division was either private-pay (high conflict; each member received her own asking price) or equal-pay (low conflict; profits were divided equally). We find that internal conflict leads to (tacit) coordination on high prices in uniform private-pay duopolies, but places private-pay teams at a competitive disadvantage in mixed duopolies. Competition is softened by transparency in uniform markets, but intensified in mixed markets. We propose an explanation of the results and discuss implications for managers and policy makers. (D43, L22, C92)
\end{abstract}

\section{Keywords}

Organizations; Conflict; Sharing Rules; Competition; Heterogeneity; Transparency; Experiment

\section{Introduction}

Organizations and firms vary substantially in how they incentivize employees and business units, and in the level of internal distributional conflict that different incentive structures impose. For example, remunerating business units according to their returns may motivate personnel, but at the same time induce conflict within the firm's supply chain (e.g., between different business units). Stronger vertical integration, on the other hand, may mitigate such conflicts and allow an organization to think and act "as one". In competitive markets, organizations with different incentive structures, and different degrees of internal conflict, coexist and compete with one another. The precise nature of each organization's incentive

\footnotetext{
Financial support from the Max Planck Society and from the European Research Council (grant ERC-AdG 295707 COOPERATION) is gratefully acknowledged. We thank Olga Gorelkina, Sebastian Georg, Oliver Kirchkamp, Botond Köszegi, Christoph March, Ivan Soraperra and Bert Willems for helpful comments on earlier versions of this paper.

*Corresponding author: Ori Weisel; oriw@ tauex.tau.ac.il. Authors are ordered alphabetically; contributions are equal.
} 
structure, and, hence, the existence of internal distributional conflicts, may be more or less visible to competitors; while the compensation scheme of key executives in publicly traded companies is disclosed in their reports, private companies are not obliged to disclose such information. This paper investigates the effect of different incentive structures, and the internal conflicts that these incentive structures impose, and of the availability of information about these incentive structures, on the ability of organizations to compete with other organizations which may, or may not, face similar conflicts.

To tackle the research question, we conduct a laboratory experiment in which two organizations compete repeatedly on price in a simple market game (Bornstein \& Gneezy, 2002). Each organization is modeled as a three-player team. Teams can be of two different types, reflecting two stylized extremes of a large spectrum of distributional conflict that organizations may face. At one end of the spectrum are equal-pay $(E)$ teams in which profits are divided equally among all members of the team and thus distributional conflict is absent by design. At the other end of the spectrum are private-pay $(P)$ teams, in which profits are distributed according to a "who asks the most, gets the most" rule. Distributional conflict arises as soon as certain members persistently claim larger shares than others. In a series of treatments, we vary whether teams face a competitor of the same type (uniform market) or of a different type (mixed market), and whether the types are mutually known (transparent market) or not (opaque market).

For markets that are both uniform and transparent extant work has shown that, somewhat paradoxically, equal-pay teams compete more aggressively than private-pay teams (Bornstein \& Gneezy, 2002; Bornstein, Kugler, Budescu, \& Selten, 2008). In uniform markets, internal distributional conflict serves as a useful tool to tacitly coordinate on higher and thus more profitable prices. We show that these results also extend to opaque markets. In contrast, the same individualistic incentives become a competitive disadvantage in mixed markets as equal-pay teams systematically set slightly lower prices and thus accumulate substantially more profits than the private-pay teams. Interestingly, we find that in mixed markets transparency plays a central role in determining price levels. With transparency, private-pay teams become more aggressive and adapt their prices downward. Without transparency, it is the equal-pay teams who become less aggressive and adapt their prices upward.

\section{Related literature and current contribution}

The present paper mainly relates to three streams of literature: (a) competition between teams, (b) teams and their optimal organization, and (c) the effects of information on competition. In this section we briefly mention a number of key results from each stream, and explain how we contribute to, and expand upon, each.

\section{(a) Competition between teams}

While there is growing interest in the experimental study of both competition (Fugger, Katok, \& Wambach, 2016; Huck, Lünser, \& Tyran, 2016; Potters \& Suetens, 2013) and the performance of differently structured teams (Hoogendoorn, Oosterbeek, \& van Praag, 2013; Weber \& Camerer, 2003), the literature that considers competition between teams rather 
than between individuals remains relatively small. A prevailing result in this literature is that competition between teams can serve to increase efforts and mitigate free riding within teams (Abbink, Brandts, Herrmann, \& Orzen, 2010; Bornstein et al., 2008; Cason, Sheremeta, \& Zhang, 2012; Charness, Rigotti, \& Rustichini, 2007; R. Chen \& Chen, 2011; Y. Chen \& Li, 2009; Goette, Huffman, \& Meier, 2006; Leibbrandt \& Sääksvuori, 2012; Nalbantian \& Schotter, 1997; Sutter \& Strassmair, 2009). Only a few papers have studied how the internal organization of competing groups affects competitive outcomes (see Sheremeta, 2015, for a review). Bornstein and Gneezy (2002) and Bornstein et al. (2008) find that, in uniform contests, competition between equal-pay teams is fiercer than competition between private-pay teams, convincingly demonstrating that the sharing rules that govern profit distribution among members of the winning team matter. Abbink et al. (2010) show that introducing intra-group punishment (inefficiently) increases teams' aggressiveness in inter-group contest. Sääksvuori, Mappes, and Puurtinen (2011) extend the analysis of intra-group punishment to mixed contests, and show that a group with punishment opportunities is competitively superior to a group without such opportunities. Similarly, introducing intra-group communication leads to increased efforts and decreased efficiency in uniform contests (Cason et al., 2012). In mixed contests, groups with intragroup communication have a competitive advantage over groups without communication (Cason, Sheremeta, \& Zhang, 2015).

We broaden the analysis in two crucial dimensions. First, we study mixed markets in which competitors have different internal profit-sharing rules, and, consequently, different degrees of internal distribution conflict. Second, acknowledging that the notion of mixed contests detrivializes the epistemic nature of the competition-in the sense that it is no longer obvious that each competitor knows how the other is organized-we manipulate the transparency of the internal profit-sharing rules. We consider transparent and opaque contests, in which the profit-sharing rule of the competitor is either known or unknown, respectively.

\section{(b) Teams and their optimal organization}

There is a large literature studying the optimal way of structuring teams. Alchian and Demsetz (1972) point out that in certain professions—lawyers, for example—organizing production by establishing profit-sharing, self-monitoring teams can increase production efficiency by circumventing the need (present in hierarchical firms) to centrally monitor individual efforts. In a similar vein, profit-sharing among team members provides insurance against idiosyncratic shocks to human capital (Lang \& Gordon, 1995) and helps committing to high quality when it cannot be easily assessed by customers (Levin \& Tadelis, 2005). A related body of work deals with the way profits are shared. In particular, the commonly employed equal-profit sharing rule has been shown to have both advantages and disadvantages: it provides optimal incentives for inequity-averse team members to exert effort (Bartling \& von Siemens, 2010) and protects the team against sabotage (Harbring \& Irlenbusch, 2011), but fails to optimally insure team members against income risk (Wilson, 1968), and may hinder efficiency by inducing teams to remain too small and uniform (Farrell \& Scotchmer, 1988; Kräkel \& Steiner, 2001). 
The extant literature on optimal organization of teams has predominantly focused on the problem of team production. Yet it has given little attention to the interaction between teams' internal structure (e.g., the specific way by which profits are shared) and the way that inter-team competition unfolds, even less to situations where competing teams differ in their internal organization, and none to transparency considerations.

\section{(c) Information about the competitor}

There has been considerable research on the effects of information about competitors' costs or demands. Available information on competitors' costs may facilitate the search for the lowest price (Stigler, 1961), shift production to the more efficient producer in a Cournot market (Shapiro, 1986), or simply foster collusion (Grether \& Plott, 1984; Schelling, 1960; Stigler, 1964). Mason \& Phillips (1997) experimentally varied whether competitors in a Cournot duopoly were informed (or not) about their respective competitor's costs of production. In their uniform markets, more information increased collusion, while in their mixed markets competitors behaved roughly in accordance with the Nash equilibrium predictions, irrespective of the information condition. Argenton and Müller (2012) make the inverse observation in a Bertrand duopoly. In their experiment, complete information about the competitor's profits fosters collusion in markets with asymmetric costs but not in markets with symmetric costs. Merely framing information on internal conflict as information on organizational cost would ignore the broad social dynamic of conflict. This is why we go beyond the existing literature by directly looking at information on the respective competitor's internal incentive structure.

\section{Experimental design and procedure}

As experimental paradigm we use a repeated Bertrand duopoly game (abstracting from production and trade), in which each of the two competitors consists of a team of three players. The game was introduced by Dufwenberg and Gneezy (2000) for individual players, and modified as a team game by Bornstein and Gneezy (2002). In every period of the game, each member $k \in\{1,2,3\}$ in team $i \in\{1,2\}$ simultaneously states an individual asking price $X_{i k} \in\{2,3, \ldots, 25\}$. The total asking price of team $i$ is denoted by $X_{i}\left(X_{i}=\sum_{k=1}^{3} X_{i k}\right)$. The team with the lower total asking price wins the competition; if the two total asking prices are equal there is a tie.

There are two types of teams, differing by how profits are divided among the three team members. Under an individualistic private-pay $(P)$ structure, each team member is paid her individual asking price if the team wins, and half her asking price in case of a tie. Under an egalitarian equal-pay (E) structure each team member receives the average asking price if the team wins, and half the average asking price if there is a tie. In both sharing rules members of the losing team receive nothing. ${ }^{1}$ Formally, the payoff of member $k$ in team $i$ in privatepay or equal-pay teams is given in Table 1.

\footnotetext{
${ }^{1}$ We label the two internal incentive structures "private-pay" and "equal-pay" since this reflects the nature of the sharing rules. Please note, however, that we did not use any loaded labels in the experimental instructions. Instead, we simply used the terms "Distribution key A" and "Distribution key B".
} 
Table 2 illustrates the experimental setup. In a $3 \times 2$ design we vary the composition of the market in terms of the competing teams' sharing rules (P vs. P, E vs. E, P vs. E), and the transparency of these sharing rules. This results in two types of uniform markets where a private-pay team is matched with another private-pay team (PP), or an equal-pay team is matched with another equal-pay team (EE), and in mixed markets where a private-pay team is matched with an equal-pay team (PE). Participants always had information about their own team's sharing rule. In the transparency $(\mathrm{t})$ treatments participants were also informed about the sharing rule of the competing team; in the opaque (o) treatments they were not.

The interaction was repeated for 120 announced periods. The team's composition, sharing rule, and corresponding competitor were determined randomly before the first period and remained constant over all 120 periods. After each period participants received feedback about their own asking price, the total asking price of their team, the total asking price of the other team, their earnings in the period, and their cumulative earnings. Before starting, paper instructions were distributed to all participants in a session. The instructions informed the participants about the two available sharing rules, the time horizon, and the information they would receive on their computer screens during the experiment. The paper instructions for the private-pay teams and for the equal-pay teams treatments were identical; type-specific information was given on-screen. The difference between the paper instructions for the "transparent" and "opaque" treatments was just one single word. ${ }^{2}$ There was no possibility of communicating neither within teams nor between teams.

The experiment was computerized using the software z-tree (Fischbacher, 2007) and participants were recruited from a pool of more than 5000 people using ORSEE (Greiner, 2015). Overall, 570 participants took part in 24 experimental sessions at the Bonn EconLab. The average session lasted about 90 minutes and participants earned about $€ 17$ on average. Individual payoffs ranged from $€ 3.50$ to $€ 47$.

\section{Theoretical considerations}

In the following we discuss some theoretical approaches to predict how the team's type (i.e., its internal incentive structure; P or E), the competitor's type, and the knowledge thereof, may affect behavior.

\section{(a) Nash equilibrium}

The unique Nash equilibrium of the stage game is that all participants demand the lowest possible individual asking price, $X_{\mathrm{ik}}=2$. This is true regardless of the team's sharing rule (for a more detailed discussion see Bornstein et al, 2008a). Furthermore, the Nash equilibrium is not affected by the competitor's sharing rule or by the knowledge thereof. Thus, the standard game theoretic prediction for the stage game is identical for all our treatments. Since the fact that the game will be played repeatedly for exactly 120 periods was made known to the participants, by backward induction it follows that the stage game equilibrium holds for each period of the repeated game as well.

\footnotetext{
${ }^{2}$ See Appendix for the paper instructions.
} 


\section{(b) Individual adaptation}

Previous results, however, indicate that teams' sharing rules do influence behavior, even when they do not affect the Nash equilibrium. In fact, in markets that are both uniform and transparent, private pay teams set substantially higher prices than equal-pay teams, and thus earn considerably higher profits (Bornstein \& Gneezy, 2002; Bornstein et al., 2008).

Bornstein and Gneezy (2002) provide a compelling argument, based on a simple process of individual adaptation, to predict and explain this result. A slightly altered version of their argument is as follows: suppose member $k$ in team $i$ is undecided between a pair of possible prices, $\bar{X}_{i k}$ and $\underline{X}_{i k}$, with $\bar{X}_{i k}>\underline{X}_{i k}$ and $\Delta=\bar{X}_{i k}-\underline{X}_{i k}$. The decision's implication on the team's winning probability is similar whether it is a private-pay team or an equal-pay team -the probability of winning is higher when the asking price is lower. However, private-pay teams and equal-pay teams differ in the way the choice between $\bar{X}_{i k}$ and $\underline{X}_{i k}$ affects the profit of the decision maker herself. Private-pay teams provide a weaker incentive to bid the lower price $\left(\underline{X}_{i k}\right)$ : if the team wins when $\underline{X}_{i k}$ was chosen, member $k$ earns $\Delta$ less than what she would have earned had she chosen $\bar{X}_{i k}$ (and had she still won the competition). In contrast, in an equal-pay team $k$ 's earnings are decreased by only $\Delta / 3$. Thus, a team member's inclination to lower her asking price, at a private cost to herself, in order to increase the team's chances of winning, is lower in private-pay teams than in equal-pay teams. Similarly, the temptation to increase personal profits at a cost to the team's chance of winning is higher in private-pay teams than in equal-pay teams.

While originally applied to transparent, uniform markets, this reasoning is actually independent of the competitor's type, as well as of whether the competitor's type is transparent or opaque. For any set of beliefs (or information) one has regarding the nature and future actions of the opposing team, members of private-pay teams have a weaker incentive to lower their bids, and a stronger incentive to increase their bids (relative to members of equal-pay teams). This leads to the following predictions: (1) prices in uniform private-pay markets will be higher than in equal-pay markets, both with and without transparency; (2) equal-pay teams will have a competitive edge over private-pay teams when competing against each other in the same market-i.e. they will win the competition more often-in both transparency conditions.

Even if equal-pay teams indeed win the competition more often, predicting price levels in mixed markets is not obvious. Three scenarios come to mind:

(1) low ("equal-pay") prices: in an attempt to compete with equal-pay teams, private-pay teams will be forced to lower their asking prices, resulting in prices similar to those of uniform equal-pay markets.

(2) high ("private-pay") prices: equal-pay teams will seize the opportunity to enjoy higher prices, resulting in prices similar to those of uniform private-pay markets.

(3) intermediate prices: both processes will take place simultaneously, resulting in prices that are higher than prices in uniform equal-pay markets and lower than prices in uniform private-pay markets. 
A way to assess the relative plausibility of the scenarios above is to apply learning models which are sensitive to the size of the incentive to lower individual bids. We consider two such models: reinforcement learning (Erev \& Roth, 1998; Roth \& Erev, 1995), a stimulus learning model that takes into account the payoff generated by the player's actions in the past; and fictitious play (Brown, 1951), a belief-based model that takes into account players' beliefs about the future actions of others. ${ }^{3}$

Despite the radically different underlying behavioral assumptions, for the uniform markets both models yield strikingly similar predictions: high prices in private-pay markets and low prices in equal-pay markets. For the mixed markets, however, reinforcement learning predicts intermediate prices (scenario 3 above), whereas fictitious play predicts that mainly equal-pay teams will adapt, resulting in high prices (scenario 2 above). Both reinforcement learning and fictitious play are mute with respect to the effect of transparency. 4

\section{(c) Effect of transparency}

In the absence of theory or previous evidence, a straightforward prediction is that transparency helps coordination on the mutually desirably outcome, i.e. high prices. This prediction is based on the intuition that (a) successful coordination requires members of each team to accurately predict the behavior of members of the other team, and (b) accurately predicting the behavior of the other team is easier when there is more information about the other team. The intuition is supported by analogy to the literature on the availability of cost information, which justifies the theoretical predictions of higher prices through more information by reference to focal points and mutually coordinated expectations of reasonable outcomes (Grether \& Plott, 1984). ${ }^{5}$

\section{Results}

Table 3 provides summary statistics across treatments on the main variables of interest: (team) asking prices, market prices, and (team) profits. In the following, we first analyze treatment differences on individual pricing behavior, and then proceed to study the implications for profits.

All figures denote arithmetic means at the team level.

Result 1. Individual asking prices are higher in uniform private-pay markets than in uniform equal-pay markets, both with and without transparency.

The large difference between private-pay and equal-pay markets in the upper-left panel of Figure 1 (PPt vs. EEt: $\mathrm{p}<0.001, \mathrm{~N}=31)^{6}$ confirms and corroborates previous findings (Bornstein \& Gneezy, 2002; Bornstein et al., 2008). In addition, as depicted in the lower-left

\footnotetext{
${ }^{3}$ See Appendix B for details.

${ }^{4}$ To the best of our knowledge there are no learning models that are sensitive to the knowledge players have about the payoff function of other players.

${ }^{5}$ It should be noted, however, that in the realm of cost information empirical studies have not corroborated this predicted effect of transparency (see Argenton \& Müller, 2012; Mason \& Phillips, 1997).

${ }^{6}$ Unless specified otherwise, we report P-values from Mann-Whitney ranksum tests (two-sided) over means per market.
} 
panel, we find the difference to be present even when the competitor's sharing rule is unknown (PPo vs. EEo: $\mathrm{p}<0.001, \mathrm{~N}=32$ ).

\section{(a) Pricing Behavior}

\section{Result 2. Transparency leads (a) to higher individual asking prices in uniform markets but (b) to lower prices in mixed markets.}

When both competitors in the market have the same internal structure, individual asking prices are higher when sharing rules are transparent. This is the case for private-pay markets (PPt vs. PPo: $\mathrm{p}=0.046, \mathrm{~N}=32$ ) and equal-pay markets alike (EEt vs. EEo: $\mathrm{p}=0.044, \mathrm{~N}=31$ ). However, the opposite happens when competitors have different internal structures. In this case, both equal-pay teams ( $\mathrm{E}(\mathrm{PEt})$ vs. $\mathrm{E}(\mathrm{PEo})$ : $\mathrm{p}=0.090, \mathrm{~N}=32)^{7}$ and private-pay teams $(\mathrm{P}(\mathrm{PEt})$ vs. $\mathrm{P}(\mathrm{PEo}): \mathrm{p}=0.050, \mathrm{~N}=32)$ ask for less when sharing rules are transparent.

Result 3. When sharing rules are transparent, individual asking prices in mixed markets are as low as in equal-pay markets (scenario 1).

As can be seen by comparing the two plots in the upper panel of Figure 1, price levels in mixed markets are virtually identical to those in uniform equal-pay markets. This is due to the fact that private-pay teams significantly lower their asking prices $(\mathrm{P}(\mathrm{PEt}) \mathrm{vs}$. $\mathrm{PPt}$ : $\mathrm{p}<0.001, \mathrm{~N}=32$ ) whereas equal-pay teams do not change their behavior ( $\mathrm{E}(\mathrm{PEt}) \mathrm{vs}$. $\mathrm{EEt}$ : $\mathrm{p}=0.594, \mathrm{~N}=31$ ).

Result 4. When sharing rules are opaque, individual asking prices in mixed markets are as high as in private-pay markets (scenario 2).

As can be seen in the lower panel of Figure 1, price levels in PEo markets are virtually identical to those in PPo markets. This is due to the fact that equal-pay teams significantly increase their asking prices ( $\mathrm{E}(\mathrm{PEo})$ vs. $\mathrm{EEo}: \mathrm{p}=0.002, \mathrm{~N}=32$ ) whereas private-pay teams do not change their behavior ( $\mathrm{P}(\mathrm{PEo})$ vs. $\mathrm{PPo}: \mathrm{p}=0.451, \mathrm{~N}=32$ ).

The contrast between Results 3 and 4 is striking. They suggest that with transparency the equal-pay teams set the tone whereas without transparency the private-pay teams do so. A plausible explanation for this finding is the relative salience of inter- and intra-group conflict. Members of equal-pay teams only face an inter-team conflict between their team and the competing team. The predetermined equal division of profits among team-members eliminates any intra-team conflict. Members of private-pay teams, on the other hand, additionally face an intra-team conflict, which has opposing behavioral implications. Whereas in the inter-team conflict it is best to ask for a low price in order to outbid the other team and win the competition, in the intra-team conflict a private-pay team member is tempted to ask for a high price in order to reap a higher profit in case of a win.

When members of a private-pay team are not aware of the competing team's sharing rule (i.e., under opaqueness), they pay more attention to the internal conflict within their own team, leading them to opt for high individual asking prices. Such behavior enables members

${ }^{7} \mathrm{E}(\mathrm{PEt})$ denotes an equal-pay team in a PEt market, etc. 
of the competing equal-pay team to increase their own asking prices to just below those of the private-pay team, such that they still win the majority of the competitions, but at higher prices (and, hence, higher profits). Under transparency, the inter-team conflict becomes more salient, so private-pay team members are driven to lower their individual asking prices in order to successfully compete with the other team, and the result is a market with low prices.

\section{Result 5. All treatment differences emerge over time.}

The observed differences between our treatments could, in principle, be a result of participants' prior beliefs and expectations about the market they are operating in, of learning and adaptation which take place during the repeated interactions, or both. If prior beliefs and expectations play a role in shaping the behavioral differences between the various treatments, at least some differences should be observed already in the very first period. This, however, is not the case. Asking prices in the first period are not different between the treatments (Kruskal-Wallis, $\mathrm{p}=0.765, \mathrm{~N}=570$ ), indicating that learning and adaptation, and not prior beliefs and expectations, are the source of the behavioral differences between the treatments.

\section{(b) Profits}

Result 6. In uniform markets, private-pay teams have an advantage over equal-pay teams, independent of transparency.

This result follows directly from result 1 . The profits of private-pay teams are $49 \%$ higher than those of equal-pay teams in transparent markets, and $76 \%$ higher in opaque markets. Thus, in uniform markets, internal distributional conflict serves as a useful tool to tacitly coordinate on higher and thus more profitable prices.

Result 7. In mixed markets, equal-pay teams have an advantage over private-pay teams, independent of transparency - they (a) ask systematically for slightly less, (b) win substantially more often, and (c) accumulate more profits.

In mixed markets teams with internal distributional conflict have a considerable competitive disadvantage. As can be seen in both right-hand plots of Figure 1, equal-pay teams manage to systematically set slightly lower prices than their private-pay competitors-both in transparent $(\mathrm{E}(\mathrm{PEt})$ vs $\mathrm{P}(\mathrm{PEt}): \mathrm{p}=0.020, \mathrm{~N}=16)$ and in opaque markets ( $\mathrm{E}(\mathrm{PEo})$ vs $\mathrm{P}(\mathrm{PEo})$ : $\mathrm{p}<0.001, \mathrm{~N}=16)^{8}$. As a result, equal-pay teams win significantly more often-both in transparent $(\mathrm{p}=0.006)$ and in opaque markets $(\mathrm{p}<0.001)$, and, as shown in Figure 2, earn significantly higher profits-30\% higher in transparent $(\mathrm{p}=0.017)$ and $57 \%$ higher in opaque markets $(\mathrm{p}=0.001)$.

\section{(c) Meta Games and Strategic Implications}

In the real world it is reasonable to assume that internal incentive structures are determined endogenously, for instance by the team's manager, and not imposed exogenously (as in the

\footnotetext{
${ }^{8}$ For comparisons of private-pay and equal-pay teams within the mixed markets, we report P-values from Wilcoxon signed rank tests (two-sided) over means per team.
} 
experiment reported here). Furthermore, such schemes do not fluctuate on a daily basis, but are rather held constant for some time before being evaluated and possibly altered.

Assuming that the choice of incentive structure is indeed endogenous, and that behavior would be the same under exogenous and endogenous incentive structures ${ }^{9}$, our results define two meta games - for the transparent and opaque cases, respectively —in which each team chooses an incentive structure which is held constant throughout the repeated interaction, and then the teams compete in a repeated Bertrand duopoly game, as in our experiment. ${ }^{10}$ Using our results to predict the mean payoff earned by each team in each period of the repeated interaction, the resulting meta games are described in Table 4.

The nature of the meta games is critically influenced by whether internal incentive structures are transparent or opaque. When incentive structures are transparent the resulting meta-game is a stag hunt game (i.e., assurance or coordination game) with two pure strategy Nash equilibria; either both managers choose private-pay incentives, or both choose equal-pay incentives, with the uniform private-pay equilibrium being both payoff dominant and risk dominant. In contrast, when internal incentive structures are opaque, the payoffs of the metagame correspond to a chicken game with two non-symmetric equilibria, where one team chooses equal pay and the other private pay (i.e., the market is mixed). The attractiveness and high profits of the uniform private-pay equilibrium in the transparent case, as opposed to the conflictual nature of the chicken game in the opaque case, suggest that teams should prefer to operate in markets with transparent sharing rules, and that once they do, they should prefer private-pay sharing rules, reasonably expecting that the competitor will do so too.

\section{Conclusion}

The internal organization of the decision-making unit is often overlooked in the study of economic decisions. This paper goes beyond the small body of previous work which has established that the internal organization of decision making teams plays a crucial role in shaping market outcomes, by analyzing the effect of transparency in markets where competitors may differ in their internal organization structure, namely in their price setting mechanism. Our internal price setting mechanism provides a stylized model of intra-team negotiations over strategic price setting. Depending on how profits are shared, these negotiations can be overshadowed by intra-team conflicts (in private-pay teams), or focus on the inter-team competition (in equal-pay teams).

Our main findings can be summarized by two contrasts: (1) When sharing rules are transparent, prices in mixed markets are as low as in uniform equal-pay markets. Yet, when sharing rules are opaque, prices in mixed markets are nearly as high as in uniform privatepay markets. (2) Transparency (as compared to opaqueness) leads to increased price levels (i.e. decreases competition) in uniform markets, but to decreased prices (i.e., increased

\footnotetext{
${ }^{9}$ Not a trivial assumption, as there is evidence from other environments that endogenous choice affects behavior via factors such as, e.g., signaling or selection (Bó, Foster, \& Putterman, 2010; Tyran \& Feld, 2006)

10 In principle, whether a team's incentive structure is transparent or opaque can also be determined endogenously. However, since we treated transparency/opaqueness as market characteristics that necessarily apply to both teams, we cannot comment on the effect of unilateral (endogenous) choices of transparency policies.
} 
competition) in mixed markets. This pattern of results is not predicted by prominent models such as Nash equilibrium, reinforcement learning, or fictitious play.

We clearly identify two factors-heterogeneity and transparency of internal incentive structures - which may affect prices and thus profits in a non-obvious way. Awareness of these factors and their effect on prices is of obvious importance to policy makers and managers alike. For example, we find the highest prices in homogeneous transparent privatepay markets, suggesting that similarly structured markets are particularly prone to tacit collusion. Market regulators might want to pay special attention to markets with similar characteristics of competitors. When deciding on the type of incentive structure to adopt, firm managers can be informed by the analysis of the meta games that our results prescribe. Depending on the transparency/opaqueness of the incentive structures, the meta game is either a relatively cooperative stag-hunt game, or a very competitive chicken game. Awareness of the game they are playing is obviously a necessary condition for making wellinformed strategic choices vis-a-vis competitors.

In conflicts, be they competitive, political, or bellicose, parties frequently accord a lot of importance to the management of their adversary's knowledge of their own type. In a competitive environment with some non-rational agents, a monopolist can preserve his monopoly by building a reputation of being irrationally aggressive. Conflicting parties also invest large resources to acquire information about their opponent's type. For example, in the negotiations to patch up the Greek debt crisis European governments invested large amounts of scarce time into verifying that the newly elected Syriza government was actually trustworthy. However, many strategic decisions have to be taken while acknowledging that one has very limited information about the adversary's decision making process. ${ }^{11}$ In our experiment, we assumed that the transparency or opaqueness of the sharing rules is a characteristic of the market, and accordingly both teams in each market are always in the same transparency condition. In real world markets, it is reasonable to assume that transparency is a strategic variable, i.e. a manager can decide whether to make internal structures transparent or to keep them opaque, irrespective of the decision of the competitor. Future research should address under which circumstances it may be optimal for a firm to unilaterally change its transparency policy.

Finally, our results have implications for the antitrust literature, particularly for the growing efforts to better understand the behavior and effect of so-called "maverick firms", i.e., firms with a more aggressive pricing policy than their (rather collusive) competitors (Breunig \& Menezes, 2008; Eckert \& West, 2004). Equal-pay teams in our experiment systematically exhibit maverick firm behavior. Antitrust authorities consider the presence of such maverick firms to be a critical inhibiting element when judging the likelihood of collusion. ${ }^{12}$ Our findings suggest that aggressive maverick behavior may be driven by a firm's internal incentive structure, and that the effectiveness of maverick firms in limiting collusion in mixed market may be limited to relatively transparent settings.

\footnotetext{
${ }^{11}$ In fact, US Defense Secretary Donald Rumsfeld (2002) might have alluded to this very problem in his famous distinction between "known unknowns" and "unknown unknowns".

${ }^{12}$ The EU Guidelines on the assessment of horizontal mergers 2004, as well as the US horizontal merger guidelines 2010.
} 


\section{Appendix}

Refer to Web version on PubMed Central for supplementary material.

\section{References}

Abbink K, Brandts J, Herrmann B, Orzen H. Intergroup conflict and intra-group punishment in an experimental contest game. The American Economic Review. 2010:420-447.

Alchian AA, Demsetz H. Production, information costs, and economic organization. The American Economic Review. 1972:777-795.

Argenton C, Müller W. Collusion in experimental Bertrand duopolies with convex costs: The role of cost asymmetry. International Journal of Industrial Organization. 2012; 30(6):508-517.

Bartling B, von Siemens FA. Equal sharing rules in partnerships. Journal of Institutional and Theoretical Economics JITE. 2010; 166(2):299-320.

Bó PD, Foster A, Putterman L. Institutions and behavior: Experimental evidence on the effects of democracy. American Economic Review. 2010; 100(5):2205-2229. [PubMed: 25076785]

Bornstein G, Gneezy U. Price competition between teams. Experimental Economics. 2002; 5(1):2938.

Bornstein G, Kugler T, Budescu DV, Selten R. Repeated price competition between individuals and between teams. Journal of Economic Behavior \& Organization. 2008; 66(3):808-821.

Breunig R, Menezes F. Empirical approaches for identifying maverick firms: An application to mortgage providers in Australia. Journal of Competition Law and Economics. 2008; 4(3):811-836.

Brown GW. Iterative solution of games by fictitious play. Activity Analysis of Production and Allocation. 1951; 13(1):374-376.

Cason TN, Sheremeta RM, Zhang J. Communication and efficiency in competitive coordination games. Games and Economic Behavior. 2012; 76(1):26-43.

Cason, TN., Sheremeta, RM., Zhang, J. Asymmetric and endogenous communication in competition between groups. 2015. Retrieved from https://papers.ssrn.com/sol3/papers.cfm? abstract_id=2556536

Charness G, Rigotti L, Rustichini A. Individual behavior and group membership. The American Economic Review. 2007; 97(4):1340-1352.

Chen R, Chen Y. The potential of social identity for equilibrium selection. The American Economic Review. 2011; 101(6):2562-2589.

Chen Y, Li SX. Group identity and social preferences. The American Economic Review. 2009; 99(1): 431-457.

Dufwenberg M, Gneezy U. Price competition and market concentration: an experimental study. International Journal of Industrial Organization. 2000; 18(1):7-22.

Eckert A, West DS. Retail gasoline price cycles across spatially dispersed gasoline stations. Journal of Law and Economics. 2004; 47(1):245-273.

Erev I, Roth AE. Predicting how people play games: Reinforcement learning in experimental games with unique, mixed strategy equilibria. American Economic Review. 1998:848-881.

Farrell J, Scotchmer S. Partnerships. Quarterly Journal of Economics. 1988; 103(2):279.doi: $10.2307 / 1885113$

Fischbacher U. z-Tree: Zurich toolbox for ready-made economic experiments. Experimental Economics. 2007; 10(2):171-178. DOI: 10.1007/s10683-006-9159-4

Fugger N, Katok E, Wambach A. Collusion in dynamic buyer-determined reverse auctions. Management Science. 2016; 62(2):518-533. DOI: 10.1287/mnsc.2014.2142

Goette L, Huffman D, Meier S. The impact of group membership on cooperation and norm enforcement: Evidence using random assignment to real social groups. 2006

Greiner B. Subject pool recruitment procedures: organizing experiments with ORSEE. Journal of the Economic Science Association. 2015; 1(1):114-125.

Grether DM, Plott CR. The effects of market practices in oligopolistic markets: an experimental examination of the ethyl case. Economic Inquiry. 1984; 22(4):479-507. 
Harbring C, Irlenbusch B. Sabotage in tournaments: Evidence from a laboratory experiment. Management Science. 2011; 57(4):611-627.

Hoogendoorn S, Oosterbeek H, van Praag M. The impact of gender diversity on the performance of business teams: Evidence from a field experiment. Management Science. 2013; 59(7):1514-1528. DOI: $10.1287 / \mathrm{mnsc} .1120 .1674$

Huck S, Lünser GK, Tyran J-R. Price competition and reputation in markets for experience goods: An experimental study. The RAND Journal of Economics. 2016; 47(1):99-117.

Kräkel M, Steiner G. Equal sharing in partnerships? Economics Letters. 2001; 73(1):105-109.

Lang K, Gordon P-J. Partnerships as insurance devices: theory and evidence. The RAND Journal of Economics. 1995:614-629.

Leibbrandt A, Sääksvuori L. Communication in intergroup conflicts. European Economic Review. 2012; 56(6):1136-1147.

Levin J, Tadelis S. Profit sharing and the role of professional partnerships. Quarterly Journal of Economics. 2005; 120(1):131-171.

Mason CF, Phillips OR. Information and cost asymmetry in experimental duopoly markets. Review of Economics and Statistics. 1997; 79(2):290-299.

Nalbantian HR, Schotter A. Productivity under group incentives: An experimental study. The American Economic Review. 1997:314-341.

Potters J, Suetens S. Oligopoly experiments in the current milenium. Journal of Economic Surveys. 2013; 27(3):439-460. DOI: 10.1111/joes. 12025

Roth AE, Erev I. Learning in extensive-form games: Experimental data and simple dynamic models in the intermediate term. Games and Economic Behavior. 1995; 8(1):164-212.

Rumsfeld, DH. DoD News Briefing - Secretary Rumsfeld and Gen Myers. 2002. Retrieved from http:// archive.defense.gov/Transcripts/Transcript.aspx?TranscriptID=2636

Sääksvuori L, Mappes T, Puurtinen M. Costly punishment prevails in intergroup conflict. Proceedings of the Royal Society of London B: Biological Sciences. 2011 rspb20110252.

Schelling, TC. The strategy of conflict. Cambridge: Mass; 1960.

Shapiro C. Exchange of cost information in oligopoly. Review of Economic Studies. 1986; 53(3):433446.

Sheremeta RM. Behavior in group contests: A review of experimental research. Available at SSRN 2673275. 2015

Stigler GJ. The economics of information. Journal of Political Economy. 1961; 69(3):213-225.

Stigler GJ. A theory of oligopoly. Journal of Political Economy. 1964; 72(1):44-61.

Sutter M, Strassmair C. Communication, cooperation and collusion in team tournaments-an experimental study. Games and Economic Behavior. 2009; 66(1):506-525.

Thorndike EL. Animal intelligence: An experimental study of the associative processes in animals. Psychological Review Monograph Supplement. 1898; 2(8):1-109.

Tyran J-R, Feld LP. Achieving compliance when legal sanctions are non-deterrent. Scandinavian Journal of Economics. 2006; 108(1):135-156. DOI: 10.1111/j.1467-9442.2006.00444.x

Weber RA, Camerer CF. Cultural conflict and merger failure: An experimental approach. Management Science. 2003; 49(4):400-415. DOI: 10.1287/mnsc.49.4.400.14430

Wilson R. The theory of syndicates. Econometrica. 1968; 36(1):119-132.

J Econ Behav Organ. Author manuscript; available in PMC 2017 December 01. 
(a) Transparent Markets
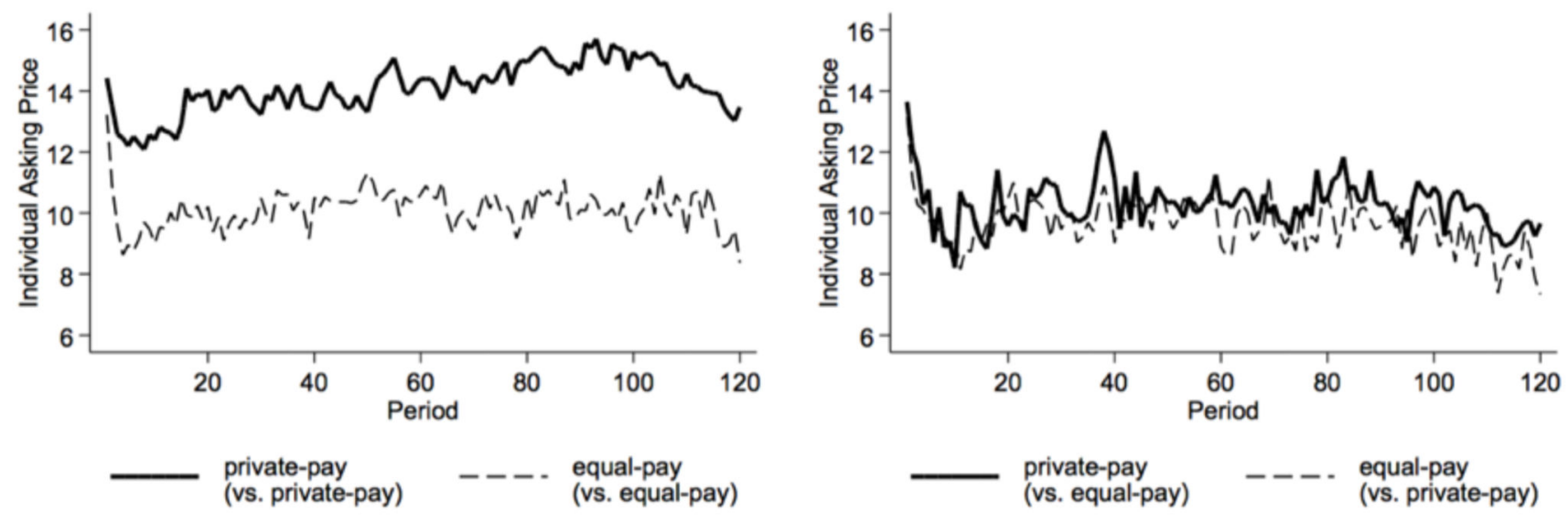

(b) Opaque Markets
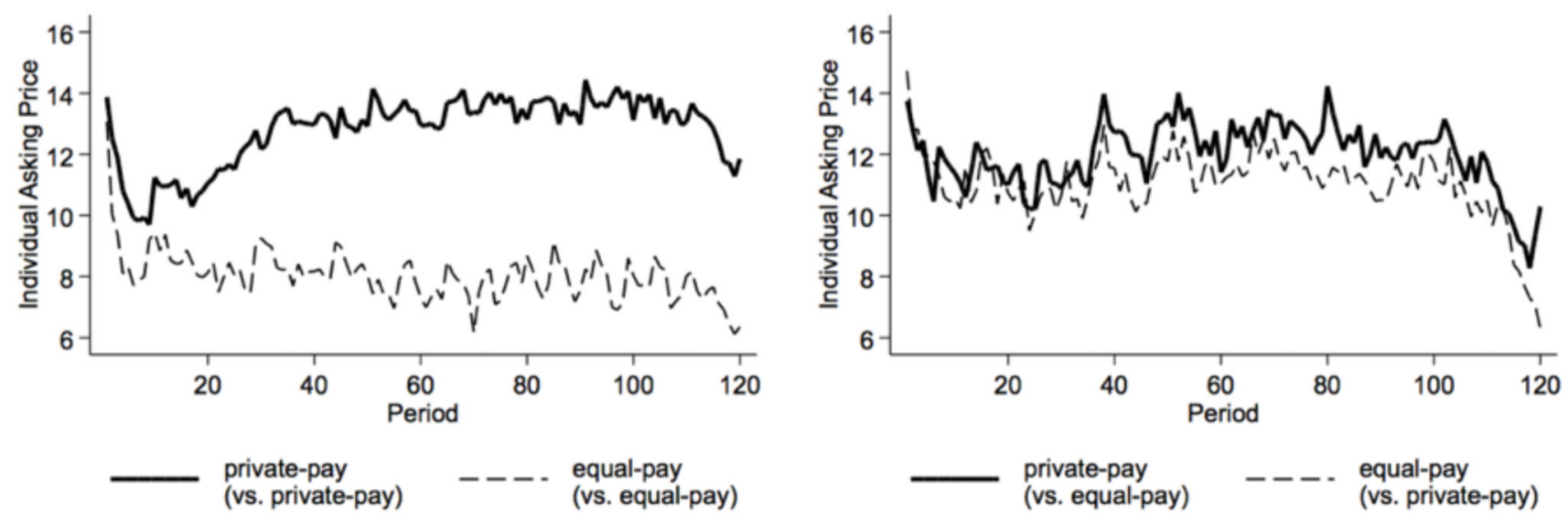

Figure 1. Individual asking prices

The graphs on the left (right) show the uniform (mixed) markets. 
(a) Transparent Markets
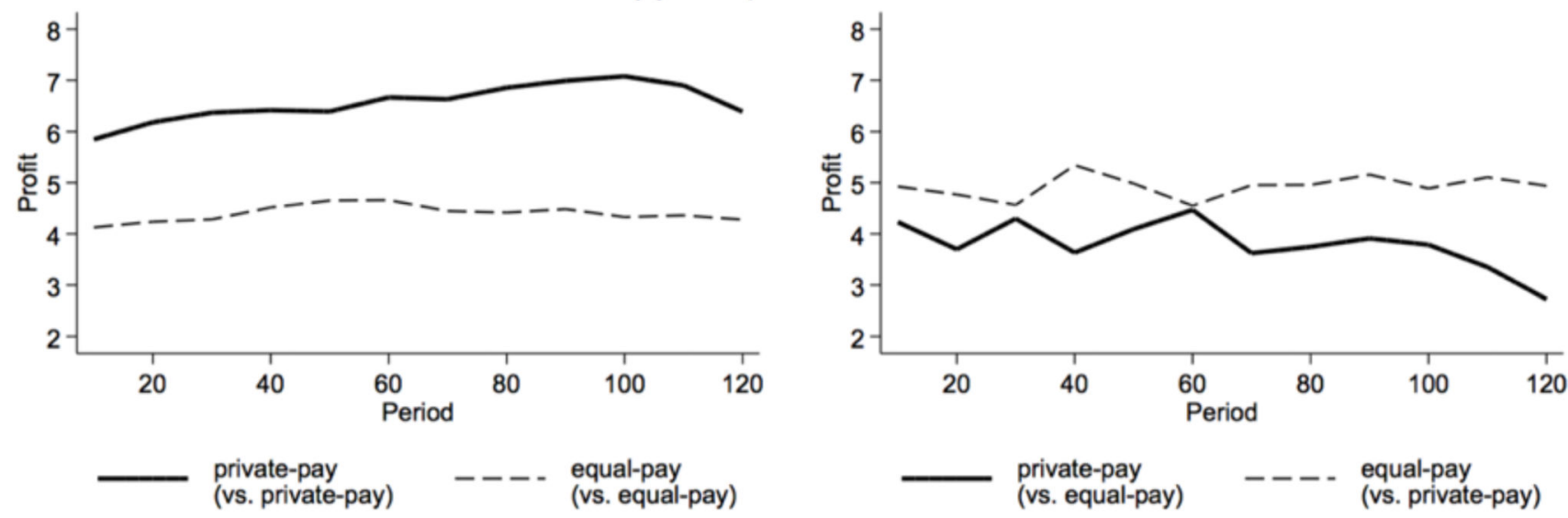

(b) Opaque Markets
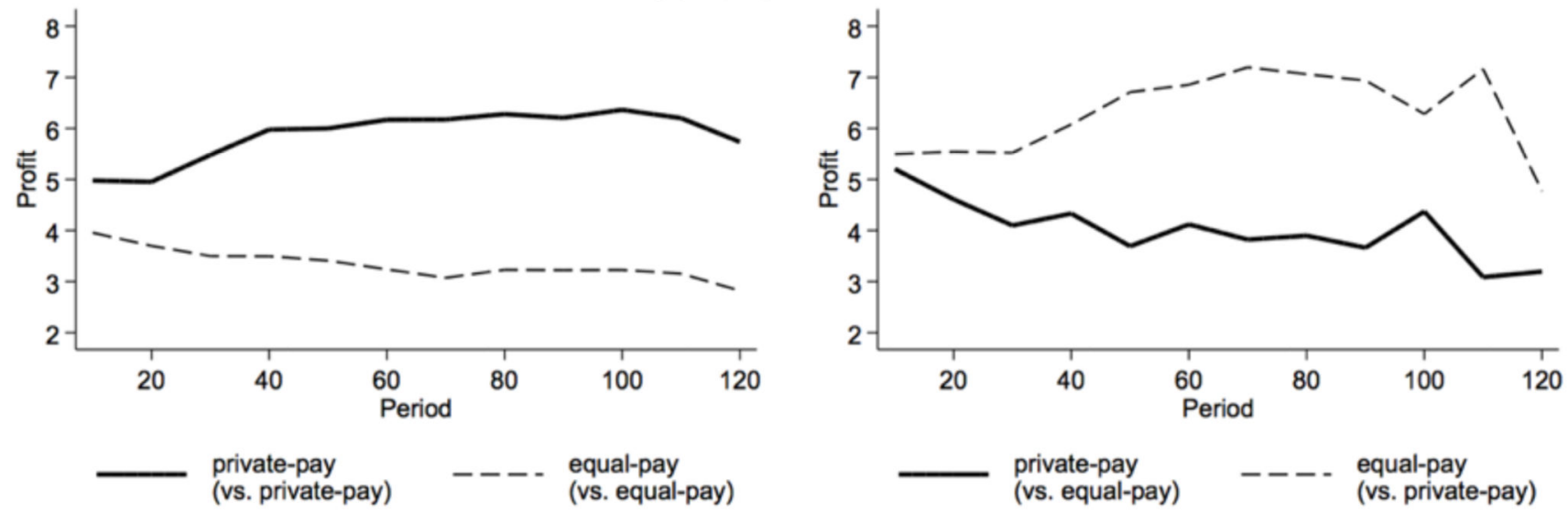

Figure 2. Profits

The graphs on the left (right) show the uniform (mixed) markets. For better readability, the 120 periods are pooled into 12 blocks of 10 periods each. 


\section{Payoff Functions.}

\section{Table 1}

$\pi_{i k}^{P}=\left\{\begin{array}{c}X_{i k}, X_{i}<X_{j} \\ X_{i k} / 2, X_{i}=X_{j} \\ 0, X_{i}>X_{j}\end{array} \quad \pi_{i k}^{E}=\left\{\begin{array}{c}X_{i} / 3, X_{i}<X_{j} \\ X_{i} / 6, X_{i}=X_{j} \\ 0, X_{i}>X_{j}\end{array}\right.\right.$


Table 2

Experimental Treatments.

\begin{tabular}{lll} 
& uniform & mixed \\
\hline \multirow{2}{*}{ transparent } & $\operatorname{PPt}\left(\mathrm{N}_{\mathrm{i}}=96 ; \mathrm{N}_{\mathrm{t}}=32 ; \mathrm{N}_{\mathrm{m}}=16\right)$ & \multirow{2}{*}{$\operatorname{PEt}\left(\mathrm{N}_{\mathrm{i}}=96 ; \mathrm{N}_{\mathrm{t}}=32 ; \mathrm{N}_{\mathrm{m}}=16\right)$} \\
& $\operatorname{EEt}\left(\mathrm{N}_{\mathrm{i}}=90 ; \mathrm{N}_{\mathrm{t}}=30 ; \mathrm{N}_{\mathrm{m}}=15\right)$ & \\
\hline \multirow{2}{*}{ opaque } & $\operatorname{PPo}\left(\mathrm{N}_{\mathrm{i}}=96 ; \mathrm{N}_{\mathrm{t}}=32 ; \mathrm{N}_{\mathrm{m}}=16\right)$ & \multirow{2}{*}{ PEo $\left(\mathrm{N}_{\mathrm{i}}=96 ; \mathrm{N}_{\mathrm{t}}=32 ; \mathrm{N}_{\mathrm{m}}=16\right)$} \\
\hline
\end{tabular}

$\mathrm{N}_{\mathrm{i}}=$ number of individual participants; $\mathrm{N}_{\mathrm{t}}=$ number of teams; $\mathrm{N}_{\mathrm{m}}=$ number of markets. 
Table 3

Summary Statistics.

\begin{tabular}{lcccccccc}
\hline & & \multicolumn{2}{c}{ team asking price } & \multicolumn{2}{c}{ market price } & \multicolumn{2}{c}{ team profit } \\
& & & uniform & mixed & uniform & mixed & uniform & mixed \\
\hline period 1 & \multirow{2}{*}{ transparent } & private & 43.25 & 40.94 & 38.69 & 34.19 & 19.34 & 16.19 \\
& & equal & 39.67 & 39.44 & 31.07 & 34.19 & 15.53 & 18.00 \\
\cline { 3 - 9 } & \multirow{2}{*}{ opaque } & private & 41.63 & 41.25 & 34.19 & 35.94 & 17.09 & 16.50 \\
& & equal & 39.22 & 44.19 & 34.19 & 35.94 & 17.09 & 19.44 \\
\hline \multirow{2}{*}{ all periods } & \multirow{2}{*}{ transparent } & private & 42.27 & 30.81 & 39.37 & 26.18 & 19.68 & 11.39 \\
& & equal & 30.28 & 28.89 & 26.40 & 26.18 & 13.20 & 14.78 \\
\cline { 3 - 8 } & \multirow{2}{*}{ opaque } & private & 38.40 & 35.93 & 35.25 & 30.92 & 17.63 & 12.02 \\
& & equal & 24.08 & 33.13 & 20.01 & 30.92 & 10.00 & 18.90 \\
\hline
\end{tabular}


Table 4

Meta Game of Choosing the Team's Internal Incentives.

Values are mean payoffs earned by each team in each period of the repeated interaction. Bold frames indicate the Nash equilibria.

\begin{tabular}{|c|c|c|c|c|c|}
\hline Transparent & private-pay & equal-pay & Opaque & private-pay & equal-pay \\
\hline \multirow[t]{2}{*}{ private-pay } & 19.8 & 14.7 & private-pay & 17.7 & 18.9 \\
\hline & 19.8 & 11.4 & & 17.7 & 12.0 \\
\hline \multirow[t]{2}{*}{ equal-pay } & 11.4 & 13.2 & equal-pay & 12.0 & 9.9 \\
\hline & 14.7 & 13.2 & & 18.9 & 9.9 \\
\hline
\end{tabular}

